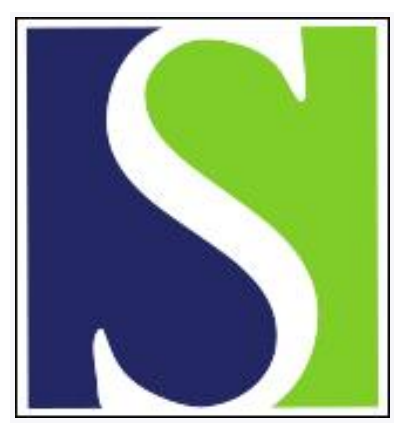

Scand J Work Environ Health 2003;29(1):5-14

https://doi.org/10.5271/sjweh.698

Issue date: Feb 2003

Factors influencing the impact of unemployment on mental health among young and older adults in a longitudinal, population-based survey

by Breslin FC, Mustard C

Affiliation: Institute for Work \& Health, 481 University Avenue, 8th Floor, Toronto, ON M5G2E9, Canada. cbreslin@iwh.on.ca

The following article refers to this text: 2014;40(5):473-482

Key terms: causation; depression; distress; longitudinal survey; mental health; older adult; population-based survey; selection; unemployment; young adult

This article in PubMed: www.ncbi.nlm.nih.gov/pubmed/12630430

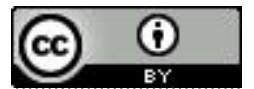




\title{
Factors influencing the impact of unemployment on mental health among young and older adults in a longitudinal, population-based survey
}

\author{
by F Curtis Breslin, PhD, ${ }^{1}$ Cam Mustard, ScD ${ }^{2}$
}

\begin{abstract}
Breslin FC, Mustard C. Factors influencing the impact of unemployment on mental health among young and older adults in a longitudinal, population-based survey. Scand J Work Environ Health 2003;29(1):5-14.
\end{abstract}

\begin{abstract}
Objectives This study examined the relationship between unemployment and mental health. It particularly emphasized the potential differences in mental health status between younger workers entering the labor market and older workers with established laborforce involvement.

Methods With the use of the National Population Health Survey in Canada, over 6000 respondents between 18 and 55 years of age in 1994 were followed up 2 years later.

Results The results suggest that, among the 31- to 55-year-olds, becoming unemployed led to increases in distress and, to some extent, clinical depression at follow-up. This association between unemployment and mental health was not found among younger adults 18 to 30 years of age. Possible explanations for the null finding among young adults, such as decreased likelihood of low household income or increased likelihood of distressed young adults completely withdrawing from the workforce, were not supported. The notion that baseline mental health affects the chances of being unemployed at the time of a 24-month follow-up were partially supported.

Conclusions These findings from a representative sample suggest that both causation and selection processes lead to an association between unemployment and distress among older adults.
\end{abstract}

Key terms causation, depression, distress, selection.

Unemployment is a key measure of the availability of work in an economy, and it represents a potentially stressful life event that can adversely affect physical and mental health $(1,2)$. Over the period 1990-1996, the slow economic growth in Canada significantly constrained the demand for young workers in the Canadian labor market. Over this period, unemployment among young adults was in the range of $12-17 \%$ and underemployment (eg, wanting to work full-time, but only able to find part-time employment) was prevalent. Over this same period, older workers with established laborforce involvement were also exposed to a high risk of unemployment arising from both the economic cycle and structural adjustment arising from technological innovation and global economic integration. For example, in the North American economy over this period, the prevalence of employment dislocation was approximate- ly $12 \%$, representing persons who lost employment over the previous 3-year period (3).

It is important to examine the effect of unemployment on mental health because distress can not only impair role functioning, it can also be an antecedent to physical health problems $(4,5)$. Unemployment has been shown to affect immunologic and cardiovascular functions adversely (6-8). The importance and implications of an association between unemployment and mental health also hinge on whether mental health issues precede (ie, selection hypothesis) or follow (ie, causation hypothesis) unemployment.

Our study sought to examine the effect of unemployment on mental health function in a representative sample of Canadian laborforce participants. We particularly emphasized potential differences in mental health function between younger workers entering the labor

1 Institute for Work \& Health, Toronto, Canada.

2 Department of Public Health Sciences, University of Toronto, Toronto, Canada.

Reprint requests to: Dr Curtis Breslin, Institute for Work \& Health, 481 University Avenue, 8th Floor, Toronto, ON M5G 2E9, Canada. [E-mail: cbreslin@iwh.on.ca] 
market and older workers with established laborforce involvement. Although unemployment has been studied for many decades, the individual and contextual factors that may modify one's experience of unemployment have yet to be fully elucidated (2).

Much of the unemployment and mental health literature focuses on moderate reactions such as emotional distress, with fewer studies examining unemployment and clinical depression. With regard to distress, longitudinal studies of adults who become unemployed show that, compared with their employed counterparts, these adults report increased distress, especially just before and just after the event (8-13). In one of the only prospective, population-based studies that assessed cases of depression and unemployment (14), those who became unemployed were at twice the risk of depression. In a recent longitudinal study of unemployment among young adults, Fergusson et al (15) did not find that unemployment was associated with a number of depressive symptoms. These apparently conflicting findings may be partly due to the fact that symptom count measures provide inconclusive evidence as to whether unemployment is associated with levels of clinical depression. Because the latter study only focused on youth, the possibility was also raised that age-related differences may exist in the impact of unemployment.

\section{Age-related differences in the impact of unemployment}

Cross-sectional studies provide additional support for the notion that the impact of unemployment differs among young and middle-aged adults (16-19). Typical of these studies, Broomhall \& Winefield (18) recruited 22 15- to 30-year-old unemployed males and 11 40- to 62 -year-old unemployed men from community organizations. The older unemployed group reported more psychological symptoms of distress than the younger group. Duration of unemployment did not appear to be a confounding variable because both groups had been unemployed for an average of 18 to 20 months. In a prospective study, Warr \& Jackson (13) found that middle-aged men showed a greater increase in psychological distress than young adults across 9 months of continuous unemployment.

Several factors have been suggested to account for age-related differences. Unemployment in this age group brings with it a potential for greater drops in social position for older adults (20). Family responsibilities and financial commitments also make unemployment particularly problematic for those in the middleage range (19). Some researchers have argued that the financial hardship resulting from unemployment and its influence on distress has been underemphasized (21). Income derived from work is central to household financial security and therefore an important influence on psychological adjustment $(20,22)$. Across countries there is variation in the reduction in income due to unemployment, variation that partly depends on whether unemployment benefits are linked to employment earnings. In some countries the financial loss can be substantial. For example, unemployed people in the United Kingdom report that their income decreases to about half their employed income (13).

Some factors may attenuate the impact of low income resulting from unemployment among young adults. For example, young adults who are already in a low-income household may already be experiencing elevated distress and consequently might not show additional distress when unemployed because the decline in income is not as marked as the transitions experienced by older adults. In addition, unemployed youth may be financially supported by their families.

Another possibility is that more young adults than older adults who have mental health problems withdraw from the workforce. Mental health problems at an early age may lead people to fail to become securely attached to the labor market. Consequently, one would hypothesize that the young adults who are still looking for a job may be less vulnerable to mental health issues than the young adults who are out of the workforce. To examine this possibility, we studied mental health among those not in the workforce and compared employed versus unemployed groups.

\section{Assessing the causal link between unemployment and mental health}

A key issue in the unemployment literature centers on the distinction between causation and selection: "Does an association between unemployment and mental health reflect the impact of this labor-market experience (ie, causation) or the influence of individual differences in prior levels of distress or depression on employment status (ie, selection)?" Determining the relative contribution of causal and selection processes has important implications for labor policy and psychosocial intervention (23).

Two issues need to be addressed to strengthen the case that unemployment leads to a decline in mental health. One issue is how to examine whether changes in employment status covary with changes in mental health. One might expect the impact of unemployment on mental health to be negative during the episode of unemployment and that negative consequences would be largely reversed once the person was reemployed. Consequently, a person who is unemployed at time 1, but reemployed by time 2 would report less time- 2 distress than someone who recently became unemployed at time 2. Consistent with this notion, several studies 
suggest that the impact of unemployment is greatest during the initial phase of unemployment (24).

The necessity of attaining information on employment and mental health status at more than one time point makes some of the research designs used to study unemployment problematic. Prospective studies on plant closings cannot assess this temporal patterning of unemployment because those unemployed have already been determined at the beginning of the study, and therefore the baseline mental health measures are contaminated. Assessing employment is not possible in studies of school leavers because all the respondents would have been students at the beginning of the study. This type of design forces one to use employment status at follow-up as a predictor and thereby makes the analysis essentially cross-sectional in nature (25). This circumstance leaves few prospective studies that have taken the temporal pattern of unemployment into account. (For an exception, see reference 24.)

The second issue is that an association between unemployment and mental health may also reflect reverse causation so that those with mental health problems are differentially selected into unemployment. This issue has also been termed the selection hypothesis. Twentytwo longitudinal studies that tested for preexisting differences between those who became unemployed (ie, selection effects) have assessed the psychological impact of unemployment among youth $(26,27)$. Seven of the 22 studies did not find preexisting differences in psychological adjustment (28-34). However, most of the studies did find significant preexisting differences, youth who became unemployed reporting more depressed affect and lower self-esteem than those gaining employment. These data suggest that causal and selection processes are not mutually exclusive. Consequently, the relationship between initial mental health status and subsequent employment status needs to be estimated as well.

We sought to address these issues on unemployment and mental health. To assess age-related differences, we performed these analyses separately for young adults (ie, 18 to 30 years of age) and older adults (ie, 31 to 55 years of age). This cutoff point was chosen for distinguishing between young and older adults because those 30 years and under are either still undergoing the school-to-work transition or have recently completed this transition (35). The temporal sequencing of employment status (eg, becoming unemployed, regaining employment) and its affect on mental health outcomes, such as distress and depression, have been assessed using a prospective study. In terms of the effect of unemployment on mental health, we hypothesized that its impact would be greater for older adults than for young adults. To assess the selection hypothesis, logistic regression was performed using baseline mental health to predict subsequent employment status. On the basis of previous research on selection effects, we hypothesized that mental health would predict subsequent employment status in both age groups. These analyses were conducted on the longitudinal component of a representative sample of Canadian men and women in the National Population Health Study. We examined respondents that were first interviewed in 1994-1995 and then reinterviewed them 2 years later.

\section{Subjects and methods}

\section{Respondents}

The respondents were part of the National Population Health Survey that began in Canada in 1994. This survey used a multistaged, stratified, random sampling procedure to select a representative sample of households across Canada (36). Each province was divided into three types of areas (major urban centers, urban towns, and rural areas) from which separate geographic or socioeconomic strata were formed. Sample households were selected and contacted in person. General information was collected from all the household members, but one member was selected to complete a detailed health survey. Respondents to the health survey had to be at least 12 years or older. Out of the 19600 households contacted, 17626 respondents provided information at time 1 (89.9\%). This longitudinal cohort was recontacted 2 years later and 15670 of the original sample provided information (88.9\%).

The primary analytic sample consisted of the respondents who were between the ages of 18 to 55 years who answered the questions at both time points. Respondents were excluded from the primary analyses if they did not have a paying job and were not looking for work (ie, not in the workforce) in either 1994 or 1996. Those younger than 18 years of age were not included because some of the measures were only asked of those 18 years and older (eg, unusual life events scale). These inclusion criteria and the item nonresponse for some variables led to a final sample size (using relative weights) of 1868 young adults (ie, 18 to 30 years of age) and 4228 older adults (ie, 31 to 55 years of age). Table 1 provides the sociodemographic and background characteristics of the sample by age group.

\section{Measures}

Sociodemographic and background measures. The baseline interview included questions regarding age, gender, marital status, and completion of high school. For marital status, the respondents were categorized as either 
Table 1. Background characteristics of the sample (with relative weights).

\begin{tabular}{|c|c|c|}
\hline \multirow[b]{2}{*}{ Variable } & \multicolumn{2}{|c|}{ Age group } \\
\hline & $\begin{array}{c}18-30 \text { years } \\
(\mathrm{N}=1868) \\
(\%)\end{array}$ & $\begin{array}{c}31-55 \text { years } \\
(\mathrm{N}=4228) \\
(\%)\end{array}$ \\
\hline \multicolumn{3}{|l|}{ Work status across time 1 and time 2} \\
\hline Employed at both times & 87.3 & 90.3 \\
\hline Employed at time 1 but unemployed at time 2 & 4.8 & 3.3 \\
\hline Unemployed at both times & 2.2 & 2.2 \\
\hline Unemployed at time 1 but employed at time 2 & 5.7 & 4.2 \\
\hline \multicolumn{3}{|l|}{ Gender } \\
\hline Male & 54.4 & 56.2 \\
\hline Female & 45.6 & 43.8 \\
\hline \multicolumn{3}{|l|}{ Marital status } \\
\hline Married or cohabitating & 42.7 & 79.1 \\
\hline $\begin{array}{l}\text { Widowed, separated, divorced, } \\
\text { or never married }\end{array}$ & 57.3 & 20.9 \\
\hline \multicolumn{3}{|l|}{ Level of education } \\
\hline Did not complete high school & 16.2 & 23.4 \\
\hline Received high school degree & 83.8 & 76.6 \\
\hline \multicolumn{3}{|l|}{ Household income inadequacy at time 1} \\
\hline Low & 12.2 & 8.3 \\
\hline Middle to high & 82.8 & 87.3 \\
\hline Missing data & 5.0 & 4.4 \\
\hline \multicolumn{3}{|l|}{ Chronic medical condition at time 1} \\
\hline Absent & 55.8 & 50.8 \\
\hline Present & 44.2 & 49.2 \\
\hline \multicolumn{3}{|l|}{ Number of unusual life events } \\
\hline None & 45.0 & 53.3 \\
\hline 1 or 2 events & 42.5 & 37.7 \\
\hline 3 or more events & 12.5 & 9.0 \\
\hline \multicolumn{3}{|l|}{ Distress score at time 1 (range 0 to 24 ) } \\
\hline 0 or 1 & 23.5 & 35.7 \\
\hline 2 to 5 & 50.0 & 47.9 \\
\hline 6 or more & 26.5 & 16.4 \\
\hline \multicolumn{3}{|l|}{ Depression status at time 1} \\
\hline No major depression & 92.1 & 94.2 \\
\hline Met criteria for major depression & 7.9 & 5.8 \\
\hline
\end{tabular}

married or in a common-law relationship or as single, widowed or divorced.

Existence of a chronic medical condition (yes, no) was a summary measure of 20 chronic conditions such as asthma, arthritis, and diabetes. The respondents were coded as having a chronic condition if they reported the presence of one or more conditions.

Household income adequacy. Household income adequacy was defined on the basis of household income and household size (36). This variable was dichotomized into either low income or middle-to-high income at both time points. For example, a household of three to four people with a total income of CAD 20000 or less was defined as low income. If the total income of the threeto four-person household was greater than CAD 20000 , then the respondent was categorized as middle-to-high income.

An indicator variable representing those who made the transition from middle-to-high income adequacy to low income adequacy was derived from income adequacy information at both time points. The respondents who reported middle-to-high income adequacy at time 1 and low-income adequacy at time 2 were coded " 1 " (weighted $\mathrm{N}=269$ or $4.6 \%$ of the sample).

Change in employment status. Respondents were considered employed if they had a paying job (either parttime or full-time) or if they were not currently working because of either a labor dispute or an "unpaid or partially paid vacation." Respondents were considered unemployed if they (i) were not working but were looking for a job, (ii) reported being laid off (ie, nonseasonal), or (iii) had resigned (Statistics Canada, 1998). For the longitudinal analyses, the respondents were grouped as follows on the basis of their employment status at both time points: (i) employed at both time points, (ii) became unemployed, (iii) unemployed at both time points, and (iv) became employed. Three dummy variables were constructed to compare the continually employed group to the other three groups.

Distress. With respect to mental health, the respondents completed a 6-item scale assessing generalized distress over the past month. They were asked how often they felt certain emotional states (ie, everything an effort, so sad nothing cheers up, nervous, restless and fidgety, hopeless, worthless) on a 5-point Likert scale (ie, "none of the time" to "all of the time"). These items were part of a pool of 500 items obtained from 22 scales measuring nonspecific psychological distress (37). As part of method research to develop a short-form scale for distress, a telephone survey was conducted in the United States in which a probability sample of 1047 respondents were administered 32 distress items elected as key indicators of this construct (38). Selection was conducted through the use of item response theory to increase comprehension of the items and maximize reliability across important subsamples of the United States population (39). The scale shows good internal reliability (Cronbach's alpha $=0.77$, unpublished observations). The distribution of distress scores was somewhat skewed; therefore a log transformation was performed to minimize bias in residuals.

Depression status. The presence of minor or major depression in the last 12 months was determined from the Composite International Diagnostic Interview (CIDI) short form (36). This brief diagnostic instrument is based on the original CIDI (40) and shows good sensitivity and specificity as compared with the full-length depression battery in the UM-CIDI (41). Compared with the original CIDI, the short form has a positive predictive value of $75.1 \%$ for major depression and a negative predictive value of $97.8 \%$. The diagnostic instrument used the 
following two features of depression to determine whether to ask further questions about depression: (i) feeling sad, blue or depressed and (ii) losing interest in most things. Respondents who experienced either of these two features most of the day, every day in a 2week period in the past 12 months were asked whether they had experienced other symptoms of depression (eg, weight loss or gain, tiredness all the time, trouble falling asleep, trouble concentrating, down on one's self, many thoughts about death). The respondents answering "yes" to four or more symptoms had a probability for caseness of 0.80 and were classified as having a major depressive episode (36).

Using the number of depressive symptoms from the brief CIDI, a bivariate analysis with the distress scale showed that the Pearson correlation coefficient was $0.41, \mathrm{P}<0.01$, suggesting that the two measures shared some variance, but were largely independent constructs.

\section{Analytic strategy}

We examined two hypotheses in the primary sample, the causation and the selection hypotheses. For the former, we examined the influence of employment transitions on distress at follow-up (ie, causation hypothesis) using a series of linear regressions. Given our interest in examining age differences, regressions were performed separately for the 18- to 30-year-olds and the 31- to 55year-olds. Linear regressions were performed to evaluate the predictors of distress. The regression included the covariates and the three dummy-coded variables for employment transition. To control for potentially confounding factors, we included gender, age, marital status, living arrangement, unusual life events, and existence of a chronic medical condition in the regression models. In addition, adjusting for distress at time 1 helped to control for other factors that influence distress and thereby strengthened the causal inferences. The inclusion of the time 1 measure of distress as a predictor violates the assumption of independent error terms. However, the purpose was to control rather than assess impact, and the focus was on the strength or overlap of other variables. An alternative approach, calculating the time- 1 to time- 2 change scores for distress, can be more complicated to interpret, have its own analytic disadvantages, and still lead to the same basic conclusions (42). For depression, we tested the same type of model using logistic regression with depression at time 1 as a covariate

In terms of the selection hypothesis, we examined the association between distress and the likelihood of unemployment at time 2 using logistic regressions. We also entered the sociodemographic variables and previous employment status into the model. To assess the effect of moderate distress and that of high distress separately, we trichotomized time 1 distress at the 33rd and 67th percentile into low, medium, and high distress, the low-distress group serving as the reference category in the logistic regressions. A parallel set of logistic regressions was performed for depression.

To explore the possibility that more young adults who have mental health problems flow out of the workforce entirely when compared with older adults, a secondary analysis examined distress levels among the young and older adults who reported not being in the workforce (ie, excluding those who were unemployed from the analyses). The "not in the workforce" (NIW) group consisted of the respondents who did not have a job and did not meet the definition for unemployment; it included those caring for family members, those ill or disabled, those attending school, and those who were retired. Next, we identified the respondents who transited in or out of the labor force over the two time points. Paralleling the coding used for transitions to unemployment, we used dummy codes to contrast the three groups who had experienced not being in the workforce (eg, employed at time 1 and not in the workforce at time 2), with those employed at both time points as the reference group. Thus those employed at both time points $(\mathrm{N}=5450)$ were compared with (i) those who were employed at time 1, but not in the workforce at time 2 ( $\mathrm{N}=283$ ), (ii) those who were not in the workforce at both time points $(\mathrm{N}=684)$, and (iii) those who were not in the workforce at time 1 but were employed at time 2 ( $\mathrm{N}=471)$.

The analyses were conducted using SAS 8.0 (SAS Institute, Cary, NC, USA). Variance estimates for the regression analyses were obtained through a bootstrapping procedure design for the National Population Health Survey (43). The procedure used weights that were based on the stratum and cluster components of the survey design, including nonresponse and poststratification adjustments.

\section{Results}

\section{Causation hypothesis}

Table 2 shows the results of the regression analyses for time 2 distress by age group. For the respondents 18 to 30 years of age, becoming unemployed and remaining unemployed were not significantly associated with time 2 distress when sociodemographic variables and time 1 distress were controlled.

In contrast, for older adults, becoming unemployed was positively associated with distress, even with time 1 distress controlled (see table 2). No other laborforce experiences (eg, repeatedly unemployed) were significantly associated with distress at time 2 . 
Table 2. Employment status predicting distress at time 2 by age group, according to the linear regression analyses. (SE =standard error)

\begin{tabular}{|c|c|c|c|c|c|c|c|c|}
\hline \multirow{4}{*}{ Employment status } & \multicolumn{8}{|c|}{ Age group } \\
\hline & \multicolumn{4}{|c|}{$18-30$ years } & \multicolumn{4}{|c|}{$31-55$ years } \\
\hline & \multicolumn{2}{|c|}{$\begin{array}{l}\text { Adjusted for background } \\
\text { variables a }^{\text {a }}\end{array}$} & \multicolumn{2}{|c|}{$\begin{array}{l}\text { Adjusted for background } \\
\text { variables }{ }^{a} \text { and time } 1 \text { distress }\end{array}$} & \multicolumn{2}{|c|}{$\begin{array}{l}\text { Adjusted for background } \\
\text { variables }^{\text {a }}\end{array}$} & \multicolumn{2}{|c|}{$\begin{array}{l}\text { Adjusted for background } \\
\text { variables }{ }^{\text {a }} \text { and time } 1 \text { distress }\end{array}$} \\
\hline & $\begin{array}{l}\text { Unstandardized } \\
\text { coefficient }\end{array}$ & SE & $\begin{array}{l}\text { Unstandardized } \\
\text { coefficient }\end{array}$ & SE & $\begin{array}{l}\text { Unstandardized } \\
\text { coefficient }\end{array}$ & SE & $\begin{array}{l}\text { Unstandardized } \\
\text { coefficient }\end{array}$ & SE \\
\hline $\begin{array}{l}\text { Employed at time } 1 \text { but } \\
\text { unemployed at time } 2\end{array}$ & -0.002 & 0.01 & -0.052 & 0.11 & $0.252^{\star}$ & 0.08 & $0.202^{*}$ & 0.07 \\
\hline $\begin{array}{l}\text { Repeatedly unemployed } \\
\text { between time } 1 \text { and time } 2\end{array}$ & 0.182 & 0.18 & 0.119 & 0.15 & 0.197 & 0.15 & 0.090 & 0.13 \\
\hline $\begin{array}{l}\text { Unemployed at time } 1 \text { but } \\
\text { employed at time } 2\end{array}$ & -0.058 & 0.10 & -0.041 & 0.09 & 0.077 & 0.08 & 0.054 & 0.08 \\
\hline
\end{tabular}

a The following background variables were controlled: gender, marital status, education level, chronic medical conditions, and number of unusual life events.

${ }^{*} \mathrm{P}<0.05$.

Table 3. Employment status predicting depression at time 2 by age group according to the logistic regression analyses. (OR $=0 d d s$ ratio, $95 \% \mathrm{Cl}=95 \%$ confidence interval)

\begin{tabular}{|c|c|c|c|c|c|c|c|c|}
\hline \multirow{4}{*}{ Employment status } & \multicolumn{8}{|c|}{ Age group } \\
\hline & \multicolumn{4}{|c|}{$18-30$ years } & \multicolumn{4}{|c|}{$31-55$ years } \\
\hline & \multicolumn{2}{|c|}{$\begin{array}{l}\text { Adjusted for background } \\
\text { variables }^{\text {a }}\end{array}$} & \multicolumn{2}{|c|}{$\begin{array}{l}\text { Adjusted for background } \\
\text { variables }^{\text {a }} \text { and time } 1 \text { depression }\end{array}$} & \multicolumn{2}{|c|}{$\begin{array}{l}\text { Adjusted for background } \\
\text { variables }^{\text {a }}\end{array}$} & \multicolumn{2}{|c|}{$\begin{array}{l}\text { Adjusted for background } \\
\text { variables a and time } 1 \text { depression }^{\text {and }}\end{array}$} \\
\hline & $\mathrm{OR}$ & $95 \% \mathrm{Cl}$ & $\mathrm{OR}$ & $95 \% \mathrm{Cl}$ & $\mathrm{OR}$ & $95 \% \mathrm{Cl}$ & $\mathrm{OR}$ & $95 \% \mathrm{Cl}$ \\
\hline $\begin{array}{l}\text { Employed at time } 1 \text { but } \\
\text { unemployed at time } 2\end{array}$ & 0.89 & $0.3-2.8$ & 0.83 & $0.3-2.6$ & $2.30^{*}$ & $1.0-\quad 5.5$ & 1.93 & $0.8-5.1$ \\
\hline $\begin{array}{l}\text { Repeatedly unemployed } \\
\text { between time } 1 \text { and time } 2\end{array}$ & 1.29 & $0.6-26.1$ & 1.26 & $0.1-25.0$ & 1.53 & $0.1-118.2$ & 1.57 & $0.1-31.6$ \\
\hline $\begin{array}{l}\text { Unemployed at time } 1 \text { but } \\
\text { employed at time } 2\end{array}$ & 1.14 & $0.4-3.1$ & 1.12 & $0.4-3.1$ & 1.13 & $0.2-\quad 6.1$ & 1.18 & $0.2-6.4$ \\
\hline
\end{tabular}

Table 4. Transitions out of the workforce predicting distress at time 2 by age group according to the linear regression analyses. (SE = standard error)

\begin{tabular}{|c|c|c|c|c|}
\hline \multirow{4}{*}{ Transition status } & \multicolumn{4}{|c|}{ Age group } \\
\hline & \multicolumn{2}{|c|}{$18-30$ years } & \multicolumn{2}{|l|}{$31-55$ years } \\
\hline & \multicolumn{2}{|c|}{$\begin{array}{l}\text { Adjusted for background } \\
\text { variables and time } 1 \\
\text { distress }^{\mathrm{a}}\end{array}$} & \multicolumn{2}{|c|}{$\begin{array}{l}\text { Adjusted for background } \\
\text { variables and time } 1 \\
\text { distress }^{\text {a }}\end{array}$} \\
\hline & $\begin{array}{l}\text { Unstandardized } \\
\text { coefficient }\end{array}$ & SE & $\begin{array}{l}\text { Unstandardized } \\
\text { coefficient }\end{array}$ & SE \\
\hline $\begin{array}{l}\text { Transition out of } \\
\text { the workforce }\end{array}$ & 0.047 & 0.10 & $0.254^{*}$ & 0.09 \\
\hline $\begin{array}{l}\text { Out of the workforce } \\
\text { at both time points }\end{array}$ & 0.017 & 0.08 & $0.196^{*}$ & 0.04 \\
\hline $\begin{array}{l}\text { Transition into } \\
\text { the workforce }\end{array}$ & 0.057 & 0.06 & 0.054 & 0.08 \\
\hline
\end{tabular}

a The following background variables were controlled: gender, marital status, education level, chronic medical conditions, and number of unusual life events.

${ }^{\star} \mathrm{P}<0.05$.
Table 3 shows the logistic regression analyses for time 2 depression. These results largely mirrored those found for distress. Older adults who became unemployed showed a marginal increase in their risk for depression, but young adults did not. No other employment transition group was associated with an increased risk for depression.

Age as an effect modifier. We examined two reasons why young adults did not show declines in mental health when shifting to unemployment. The first question was "Are young adults who are susceptible to mental health problems more likely to leave the workforce completely than older adults? If this were the case, then young adults who are unemployed may be more "distress resistant" than older, unemployed adults.

Table 4 shows that, as with the transition between employment and unemployment, those less than 31 
years of age did not show increases in distress during their transition to not being in the workforce, while older adults did $(\mathrm{P}<0.05)$. This finding suggests that the lack of a significant unemployment-distress association for young adults did not appear to be due to a high rate of distressprone young adults flowing out of the workforce rather than being due to unemployment.

A second possibility was that younger adults may be less likely for their transition to lead to an inadequate household income. To test this hypothesis, we used our employment-unemployment status variables to predict the dichotomous measure of transition to inadequate household income from time 1 to time 2. Table 5 shows that, in both age groups, becoming unemployed increased the likelihood of transition to an inadequate household income at time $2(\mathrm{P}<0.05)$. This finding suggests that a lack of change in distress among the younger adults who became unemployed was not due to a reduced likelihood of a transition to a low household income.

\section{Selection}

The longitudinal data also provided the opportunity to examine whether mental health at time 1 was associated with an increased risk of unemployment at time 2 (ie, the selection hypothesis). Table 6 shows the odds ratios for the predictors of employment status at time 2 (unemployed $=1$ ). For the respondents 18 to 30 years of age, a high distress score at time 1 showed an approximately twofold increase in the probability of being unemployed at time 2. This association was slightly increased when employment status at time 1 was controlled. For the respondents 31 to 55 years of age, there was a similar increase in risk for those experiencing high distress. A nonsignificant association between moderate distress and subsequent employment status was also found for both age groups.

With regard to time-1 depression predicting employment status at time 2, we found no significant association for either age group (table 7).

\section{Discussion}

A recent review noted several longitudinal studies showing that unemployment is associated with a decline in mental health (4). However, these studies have often focused on nonrepresentative samples or did not use analytic strategies that directly tested the influence of becoming unemployed on distress. In our study, we found that older adults (ie, those 31 to 55 years old) who became unemployed were more likely to report elevated distress at time 2 than those who remained employed.

Table 5. Employment-unemployment status predicting risk of transition to inadequate income by age according to the logistic regression analyses. ${ }^{a}(\mathrm{OR}=$ odds ratio, $95 \% \mathrm{Cl}=95 \%$ confidence interval)

\begin{tabular}{|c|c|c|c|c|}
\hline \multirow{3}{*}{ Employment status } & \multicolumn{4}{|c|}{ Age group } \\
\hline & \multicolumn{2}{|c|}{$18-30$ years } & \multicolumn{2}{|c|}{$31-55$ years } \\
\hline & $\mathrm{OR}$ & $95 \% \mathrm{Cl}$ & $\mathrm{OR}$ & $95 \% \mathrm{Cl}$ \\
\hline $\begin{array}{l}\text { Employed at time } 1 \text { but } \\
\text { unemployed at time } 2\end{array}$ & 3.63 & $1.5-8.9$ & 4.19 & $1.9-9.0$ \\
\hline $\begin{array}{l}\text { Repeatedly unemployed } \\
\text { between time } 1 \text { and time } 2\end{array}$ & 3.16 & $0.8-12.5$ & 4.00 & $1.4-11.0$ \\
\hline $\begin{array}{l}\text { Unemployed at time } 1 \text { but } \\
\text { employed at time } 2\end{array}$ & 1.15 & $0.4-3.2$ & 1.50 & $0.6-3.5$ \\
\hline
\end{tabular}

a Logistic regression: controlling for distress at time 1, gender, marital status, education level, presence of chronic medical condition, and unusual life events.

Table 6 . Distress predicting unemployment status at time 2 by age group according to the logistic regression analyses. (OR $=0$ odds ratios, $95 \% \mathrm{Cl}=95 \%$ confidence interval)

\begin{tabular}{|c|c|c|c|c|c|c|c|c|}
\hline \multirow{4}{*}{$\begin{array}{l}\text { Degree } \\
\text { of distress }\end{array}$} & \multicolumn{8}{|c|}{ Age group } \\
\hline & \multicolumn{4}{|c|}{$18-30$ years } & \multicolumn{4}{|c|}{$31-55$ years } \\
\hline & \multicolumn{2}{|c|}{$\begin{array}{l}\text { Adjusted for background } \\
\text { variables }^{\mathrm{a}}\end{array}$} & \multicolumn{2}{|c|}{$\begin{array}{l}\text { Adjusted for background } \\
\text { variables }^{\text {a }} \text { and time } 1 \text { employment }\end{array}$} & \multicolumn{2}{|c|}{$\begin{array}{l}\text { Adjusted for background } \\
\text { variables }^{\mathrm{a}}\end{array}$} & \multicolumn{2}{|c|}{$\begin{array}{l}\text { Adjusted for background } \\
\text { variables }^{\text {a }} \text { and time } 1 \text { employmen }\end{array}$} \\
\hline & $\mathrm{OR}$ & $95 \% \mathrm{Cl}$ & $\mathrm{OR}$ & $95 \% \mathrm{Cl}$ & $\mathrm{OR}$ & $95 \% \mathrm{Cl}$ & $\mathrm{OR}$ & $95 \% \mathrm{Cl}$ \\
\hline Low & .. & .. & .. & .. & .. & .. & .. & .. \\
\hline Moderate & 1.41 & $0.8-2.6$ & 1.52 & $0.8-2.9$ & 1.25 & $0.8-1.9$ & 1.22 & $0.8-1.8$ \\
\hline High & $1.93^{*}$ & $0.9-3.9$ & $2.12^{\star \star}$ & $1.0-4.4$ & $2.01^{* *}$ & $1.3-3.2$ & $1.79^{\star \star}$ & $1.1-2.9$ \\
\hline
\end{tabular}

a The following background variables were controlled: gender, marital status, education level, chronic medical conditions, and number of unusual life events.

${ }^{\star} \mathrm{P}<0.10,{ }^{\star *} \mathrm{P}<0.05$. 
Table 7. Depression category predicting unemployment status by age group according to the logistic regression analyses. (OR $=0 d d s$ ratio, $95 \% \mathrm{Cl}=95 \%$ confidence interval)

\begin{tabular}{|c|c|c|c|c|c|c|c|c|}
\hline \multirow{4}{*}{$\begin{array}{l}\text { Depression } \\
\text { category }\end{array}$} & \multicolumn{8}{|c|}{ Age group } \\
\hline & \multicolumn{4}{|c|}{$18-30$ years } & \multicolumn{4}{|c|}{$31-55$ years } \\
\hline & \multicolumn{2}{|c|}{$\begin{array}{l}\text { Adjusted for background } \\
\text { variables a }^{\text {a }}\end{array}$} & \multicolumn{2}{|c|}{$\begin{array}{l}\text { Adjusted for background } \\
\text { variables }{ }^{a} \text { and time } 1 \text { depression }\end{array}$} & \multicolumn{2}{|c|}{$\begin{array}{l}\text { Adjusted for background } \\
\text { variables }^{\text {a }}\end{array}$} & \multicolumn{2}{|c|}{$\begin{array}{l}\text { Adjusted for background } \\
\text { variables }{ }^{\mathrm{a}} \text { and time } 1 \text { depression }\end{array}$} \\
\hline & $\mathrm{OR}$ & $95 \% \mathrm{Cl}$ & $\mathrm{OR}$ & $95 \% \mathrm{Cl}$ & $\mathrm{OR}$ & $95 \% \mathrm{Cl}$ & $\mathrm{OR}$ & $95 \% \mathrm{Cl}$ \\
\hline Not major & .. & .. & .. & .. & .. & .. & .. & .. \\
\hline Major & 1.56 & $0.8-3.1$ & 1.53 & $0.7-3.3$ & 1.61 & $0.8-3.0$ & 1.80 & $0.9-3.7$ \\
\hline
\end{tabular}

a The following background variables were controlled: gender, marital status, education level, chronic medical conditions, and number of unusual life events.

Our analyses of cases of clinical depression showed a similar, but somewhat weaker association. Although age as an effect modifier has been noted before (18), our study, by using a general population sample, provides further support for age as a moderator of the effects of unemployment.

One possibility we explored to account for age differences was the relationship between financial hardship and distress. We hypothesized that fewer young adults may experience a drop to an inadequately low income, perhaps because they either had a low income even when employed or because financial support from their family of origin prevented the decline in income. However, both age groups showed a significant increase in the likelihood of shifting to an inadequate income if they became unemployed, and therefore this hypothesis was not supported.

Another possibility we explored to account for age as an effect modifier was whether those susceptible to declines in mental health shifted out of the workforce completely. If this shift had occurred for more young adults than older adults, it may have led to more "distress resistant" young adults among the unemployed. However, this hypothesis was also not confirmed. Thus, although older adults seemed to evidence more distress as a result of unemployment than younger adults, the mechanisms behind this age-related difference must still be determined. Nevertheless, our findings confirmed that, in a general population sample, the unemploymentdistress association exists among older adults. Whether the results can be explained by differences between generations, such as lower employment commitment, was not possible to assess, but it is a plausible hypothesis to be explored in future research. Another possibility not assessed in our study was that older adults perceive their chances of regaining employment as lower than young adults do, and therefore their distress is increased. Direct measures of these types of psychological constructs would be useful for accounting for age-related differences.
Our analyses did not show increased distress at time 2 among those unemployed at both time points. This result is consistent with the results of at least two longitudinal studies that reported that people who did not find stable reemployment did not seem to show progressively greater distress $(11,24)$. Indeed, Morrell et al (24) reported an odds ratio of below 1.0 for this group (when compared with those employed), the finding suggesting an adaptation to unemployment. This result underscores the importance of assessing respondents who become unemployed and those who remain unemployed separately.

The fact that there was no statistically significant association between unemployment and clinical depression could be explained in at least two ways. First, the incidence of clinical depression was low $(<10 \%)$ and thereby reduced the power to detect associations. Second, many cases of clinical depression may have a substantial biological component that limits the influence of negative life events such as employment. This relative stability of depression may contrast to levels of distress that are more affected by unemployment, at least among older adults.

With regard to the selection hypothesis, we used a multivariate approach to examine whether mental health influences the likelihood of unemployment. For both younger and older adults, high distress significantly predicted subsequent employment status. A few studies have reported univariate analyses suggesting antecedent differences in mental health for those who become unemployed. (As an example, see reference 44.) Our finding that unemployment predicted distress and distress predicted employment status substantiated, in a population-based study, that selection processes also appear to be operating. Possible mechanisms for how mental health increases the risk of unemployment include motivational and coping deficits. These types of deficits are cardinal features of stress reactions and depression. Thus, while reemployment appears to reverse the distress associated with unemployment for the most part, high 
distress increases the risk of not becoming reemployed. This finding has important implications for understanding the well-established adverse effects of unemployment on physical health. That is, distress prolongs unemployment and, in turn, the psychosomatic reaction to this stressor leads to longer-term negative health effects.

Our study had both strengths and limitations. The large and diverse sample permited generalizability to a wide segment of the Canadian population. One limitation of the study was the 2-year interval between interviews. This interval meant that some of the respondents may have experienced multiple periods of employment or may have been unemployed for much longer time periods than others. Given that distress is greatest just before and immediately after unemployment, our estimates of the association may have been reduced by the gap between the measurements. Another limitation was related to the time frame of the distress scale, namely, distress in the past month was assessed, whereas employment was based on current status. This difference in time frame may have led some people who were unemployed to report their distress several months after they had become unemployed.

In summary, our results build on existing findings that suggest that age moderates the effect of unemployment on mental health. This result does not necessarily mean, however, that younger adults are not adversely affected by unemployment. For example, positive responses about such factors as substance use and abuse may occur more frequently among young adults (15). In further research on the diverse psychological and behavioral reactions that people have to unemployment, it appears that the developmental stage of a person should be taken into account. Our finding that distress predicted unemployment in this population-based survey is consistent with the results of other studies of selection effects. This observation has applied relevance. It suggests that public health initiatives and clinical services need to be aware of the impact of high distress on laborforce status.

\section{References}

1. Dooley D, Fielding J, Levi L. Health and unemployment. Ann Rev Public Health 1996;17:449-65.

2. Lavis JN, Mustard CA, Payne JI, Farrant MS. Work-related population health indicators. Can J Public Health 2001; 92(1):72-8.

3. Osterman P. Securing prosperity: the American labour market: how it has changed and what to do about it. Princeton (NJ): Princeton University Press; 1999.

4. Kasl S, Rodriguez E, Lach K. The impact of unemployment on health and well-being. In: Dohrenwend BP, editor. Adversity, stress, and psychopathology. New York (NY): Oxford University Press; 1998. p 111-31.
5. Taylor SE, Repetti RL, Seeman T. Health psychology: what is an unhealthy environment and how does it get under the skin? Annu Rev Psychol 1997;48:411-47.

6. Siegrist J, Matschinger H, Cremer P, Seidel, D. Atherogenic risk in men suffering from occupational stress. Atherosclerosis 1988;69:218.

7. Mattiasson I, Lindgärde F, Ake Nilsson J, Theorell T. Threat of unemployment and cardiovascular risk factors: longitudinal study of quality of sleep and serum cholesterol concentrations in men threatened with redundancy. BMJ 1990;301: 461-6.

8. Arnetz BB, Brenner SO, Levi L, Hjelm R, Petterson IL, Wasserman $J$, et al. Neuroendocrine and immunologic effects of unemployment and job insecurity. Psychother Psychosom 1991;55(2-4):76-80.

9. Gore S. The effect of social support in moderating the health consequences of unemployment. J Health Soc Behav 1978; 19(6):157-65.

10. Hamilton VH, Merrigan P, Dufresne E. Down and out: estimating the relationship between mental health and unemployment. Health Economics 1997;6:397-406.

11. Kasl S, Gore S, Cobb S. The experience of losing a job: reported changes in health, symptoms, and illenss behavior. Psychosom Med 1975;37(106):122.

12. Linn M, Sandifer R, Stein S. Effects of unemployment on mental and physical health. Am J Public Health 1985;75(5): $502-6$.

13. Warr P, Jackson P. Factors influencing the psychological impact of prolonged unemployment and of re-employment. Psychol Med 1985;15:795-807.

14. Dooley D, Catalano R, Wilson G. Depression and unemployment: panel findings from the epidemiologic catchment area study. Am J Community Psychol 1994;22(6):745-65.

15. Fergusson DM, Horwood LJ, Woodward LJ. Unemployment and psychosocial adjustment in young adults: causation or selection? Soc Sci Med 2001;53(3):305-20.

16. Banks MH, Clegg CW, Jackson PR, Kemp NJ, Stafford EM, Wall TD. The use of the General Health Questionnaire as an indicator of mental health in occupational studies. J Occup Psychol 1980;53:187-94.

17. Rowley KM, Feather NT. The impact of unemployment in relation to age and length of unemployment. J Occup Psychol 1987;60(4):323-32.

18. Broomhall HS, Winefield AH. A comparison of the affective well-being of young and middle-aged unemployed men matched for length of unemployment. Br J Med Psychol 1990;63 (Pt 1):43-52.

19. Jackson P, Warr P. Unemployment and psychological illhealth: the moderating role of duration and age. Psychol Med 1984;14:605-14.

20. Warr PB. Work, unemployment and mental health. Oxford: Claredon Press; 1987.

21. Fryer D. Employment deprivation and personal agency during unemployment: a critical discussion of Jahoda's explanation of the psychological effects of unemployment. Soc Behav 1986;1(1):3-23.

22. Jahoda M. Reflections on Marienthal and after. J Occup Organ Psychol 1992;65,355-8.

23. Fryer D. Unemployment and mental health: hazards and challenges of psychology in the community. In: Isaksson K, Hogstedt C, Eriksson C, Theorell T, editors. Health effects of the new labour market. New York (NY): Kluwer Academic / Plenum Publishers; 2000. p 11-23.

24. Morrell S, Taylor R, Quine S, Kerr C, Western J. A cohort 
study of unemployment as a cause of psychological disturbance in Australian youth. Soc Sci Med 1994;38(11):155364.

25. Kessler RC. The interplay of research design strategies and data analysis procedures in evaluating the effects of stress on health. In: Kasl S, Cooper C, editors. Stress and health: issues in research methodology. New York (NY): Wiley; 1987. p 113-40.

26. O'Brien GE, Feather NT. The relative effects of unemployment and quality of employment on the affect, work values and personal control of adolescents. J Occup Psychol 1990;63(3):151-65.

27. Winefield AH, Tiggemann M. Psychological correlates of employment and unemployment: effects, predisposing factors, and sex differences. J Occup Psychol 1985;58(3):22942.

28. Schaufeli WB. Youth unemployment and mental health: some Dutch findings. J Adolesc 1997;20:281-92.

29. Graetz B. Health consequences of employment and unemployment: longitudinal evidence for young men and women. Soc Sci Med 1993;36(6):715-24.

30. Banks MH, Jackson PR. Unemployment and risk of minor psychiatric disorder in young people: cross-sectional and longitudinal evidence. Psychol Med 1982;12:789-98.

31. Winefield AH, Winefield HR, Tiggemann M, Goldney RD. A longitudinal study of the psychological effects of unemployment and unsatisfactory employment on young adults. J Appl Psychol 1991;76(3):424-31.

32. Gurney RM. The effects of unemployment on the psychosocial development of school-leavers. J Occup Psychol 1980;53:205-13.

33. Winefield AH, Tiggemann M. Length of unemployment and psychological distress: longitudinal and cross-sectional data. Soc Sci Med 1990;31(4):461-5.

34. Layton C. Change-score analyses on the GHQ and derived subscales for male school leavers with subsequent differing work status. Pers Individ Differ 1986;7(3):419-22.

35. Bowlby G. The school-to-work transition. Ottawa (Ontario): Statistics Canada; 2000. Catalogue no 75-001-XPE, 43-48.

36. Statistics Canada. National population health survey overview 1996-97. Ottawa (Ontario): Statistics Canada; 1998.

37. Wade TJ, Cairney J. Age and depression in a nationally representative sample of Canadians: a preliminary look at the national population health survey. Can J Public Health 1997; 88(5):297-302.

38. Kessler RC, Mroczek DK. Measuring the effects of medical interventions. Med Care 1995;33(4 suppl):AS109-19.

39. Wade TJ, Cairney J. The effect of sociodemographics, social stressors, health status, and psychosocial resources on the age-depression relationship. Can J Public Health 2000;91(4): 307-12.

40. Kessler RC, Andrews G, Mroczek DK, Ustun B, Wittchen HU. The World Health Organization composite international diagnostic interview short-form (CIDI-SF). Int $\mathrm{J}$ Methods Psychiatr Res 1998;7(4):171-85.

41. Patten S, Brandon-Christie J, Devji J, Sedmak B. Performance of the CIDI short form for major depression in a community sample. Chronic Dis Can 2000;21:68-72.

42. Bachman JG, O'Malley PM, Johnston LD. Drug use among young adults: the impacts of role status and social environment. J Pers Soc Psychol 1984;47(3):629-45.

43. Yeo D, Mantel H, Liu TP. Bootstrap variance estimation for the national population health survey: 1999 proceedings of the survey research methods section. Baltimore (MD): American Statistical Association; 1999.

44. Hammarstrom A. Health consequences of youth unemployment. Public Health 1994;108:403-12.

Received for publication: 5 February 2002 